TABLE 1. Hemodynamic data before and 15 minutes after start of iloprost inhalation

\begin{tabular}{|c|c|c|c|c|c|}
\hline & \multirow{2}{*}{$\begin{array}{l}\text { Before } \\
\text { iloprost }\end{array}$} & \multirow[b]{2}{*}{ After iloprost } & \multicolumn{2}{|c|}{ Change } & \multirow{2}{*}{$\begin{array}{c}P \\
\text { value* }\end{array}$} \\
\hline & & & Mean \pm SD & $\%$ & \\
\hline Mean pulmonary arterial pressure (mm Hg) & $31.6 \pm 6.6$ & $26.1 \pm 3.1$ & $5.5 \pm 5.5$ & -17.4 & .01 \\
\hline Mean arterial pressure $(\mathrm{mm} \mathrm{Hg})$ & $71.6 \pm 9.7$ & $70.8 \pm 12.6$ & $0.8 \pm 13.2$ & -1.1 & NS \\
\hline Cardiac index $\left(\mathrm{L} \cdot \min ^{-1} \cdot \mathrm{m}^{-2}\right)$ & $3.0 \pm 0.5$ & $3.2 \pm 0.7$ & $0.2 \pm 0.5$ & +7.4 & NS \\
\hline Pulmonary vascular resistance (dyne $\cdot \mathrm{s} \cdot \mathrm{cm}^{-5}$ ) & $394.3 \pm 128.1$ & $289.6 \pm 94.6$ & $104.7 \pm 73.8$ & -26.6 & .002 \\
\hline Systemic vascular resistance (dyne $\cdot \mathrm{s} \cdot \mathrm{cm}^{-5}$ ) & $1016.1 \pm 228.2$ & $976.0 \pm 332.1$ & $12.7 \pm 253.8$ & -1.2 & NS \\
\hline
\end{tabular}

All data are mean \pm SD. NS, Not significant.

*By paired $t$ test.

tacyclin $<3$ minutes vs 20-30 minutes for iloprost). Aerosolized iloprost has shown vasodilating potency similar to that of inhaled NO in secondary PHT, and it actually appears to be superior in primary PHT. $^{2}$

The intraoperative use of aerosolized prostanoids has been reported in only a few surgical cases, ${ }^{3}$ probably because of concerns regarding impaired platelet function. Both inhaled prostacyclin and NO are associated with impaired platelet aggregation in vitro $^{4,5}$ but are without signs of platelet dysfunction in vivo. ${ }^{4}$ Increases in mediastinal drainage or transfusion requirements were not observed in any of our cases.

In conclusion, the intraoperative use of aerosolized iloprost is a clinical alternative to NO that warrants further comparative studies.

\section{References}

1. Haddad E, Lowson SM, Johns RA, Rich GF. Use of inhaled nitric oxide perioperatively and in intensive care patients. Anesthesiology. 2000;92: $1821-5$.

2. Hoeper MM, Olschewski H, Ghofrani HA, Wilkens H, Winkler J, Borst MM, et al. A comparison of the acute hemodynamic effects of inhaled nitric oxide and aerosolized iloprost in primary pulmonary hypertension. German PPH study group. J Am Coll Cardiol. 2000;35:176-82.

3. Schroeder RA, Wood GL, Plotkin JS, Kuo PC. Intraoperative use of inhaled $\mathrm{PGI}_{2}$ for acute pulmonary hypertension and right ventricular failure. Anesth Analg. 2000;91:291-5.

4. Haraldsson A, Kieler-Jensen N, Wadenvik H, Ricksten SE. Inhaled prostacyclin and platelet function after cardiac surgery and cardiopulmonary bypass. Intensive Care Med. 2000;26:188-94.

5. Högman M, Frostell C, Hedenstierna G. Bleeding time prolongation and NO inhalation. Lancet. 1993;341:1664-5.

\title{
Refractory chylothorax after lung transplantation for lymphangioleiomyomatosis successfully cured with instillation of povidone
}

Gaëlle Dauriat, MD, ${ }^{a}$ Olivier Brugière, MD, ${ }^{a}$ Hervé Mal, MD, ${ }^{a}$ Juliette Camuset, MD, ${ }^{a}$ Yves Castier, MD, ${ }^{b}$

Guy Lesèche, MD, ${ }^{b}$ and Michel Fournier, MD, ${ }^{a}$ Clichy, France

From the Departments of Pneumology and Vascular and Thoracic Surgery, ${ }^{\mathrm{b}}$ Hôpital Beaujon, Clichy, France.

Received for publication Dec 23, 2002; accepted for publication Feb 11, 2003.

Address for reprints: Gaëlle Dauriat, MD, Service de Pneumologie, Hôpital Beaujon, Assistance Publique-Hôpitaux de Paris, 100 boulevard du Général Leclerc, 92110, Clichy, France (E-mail: gaelle.dauriat@bjn.ap-hop-paris. fr).

J Thorac Cardiovasc Surg 2003;126:875-7

Copyright $\odot 2003$ by The American Association for Thoracic Surgery $0022-5223 / 2003 \$ 30.00+0$

doi:10.1016/S0022-5223(03)00716-5

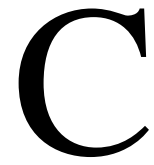

hylothorax is a well-known complication after lung transplantation for lymphangioleiomyomatosis. Standard therapeutic options, including dietary regimens containing medium-chain triglycerides, chest tube drainage, and thoracic duct ligation have previously been reported as successful in managing chylothorax in lung transplant recipients with lymphangioleiomyomatosis. ${ }^{1,2}$

We report a patient with refractory chylothorax after bilateral lung transplantation for lymphangioleiomyomatosis that failed to respond to all conventional therapies. After a 7-month postoperative period of continuous chylous effusion, the injection of povidone (INN polyvidone) through the chest tube was able to stop the chylous effusion definitively and rapidly. 


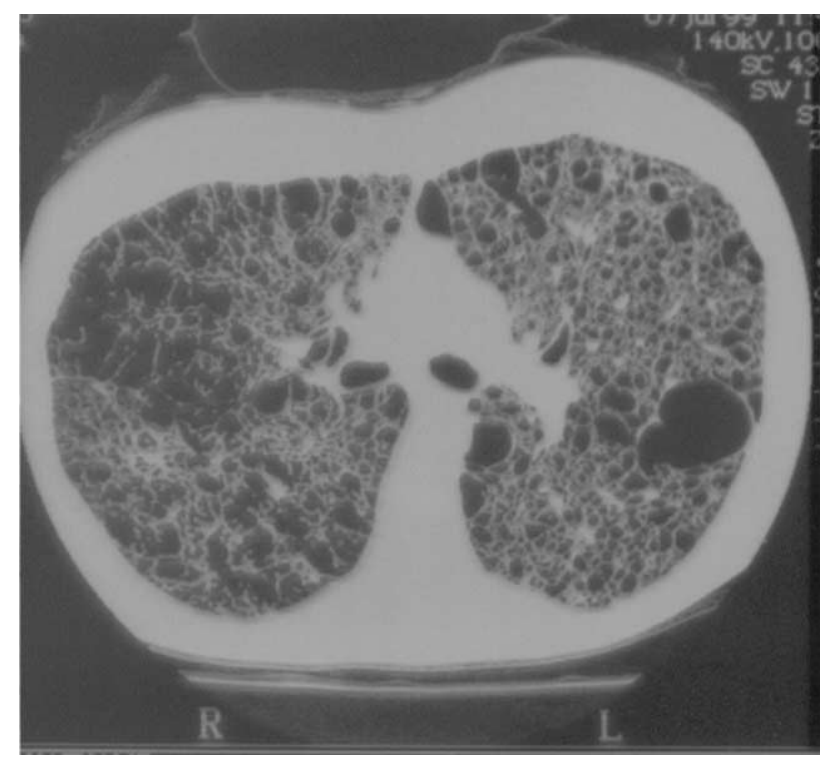

Figure 1. Computed tomographic scan before LT.

\section{Clinical Summary}

A 35-year-old woman with end-stage lymphangioleiomyomatosis was referred to our center for lung transplantation (LT). Lymphangioleiomyomatosis had been revealed 6 years before by bilateral pneumothoraces that required bilateral pleurodesis by videothoracoscopy. At admission, the patient was dyspneic at rest, requiring high-flow oxygen supplementation (12 L/min). Computed tomographic scan revealed large cysts (Figure 1). On May 21, 2000, bilateral LT was performed. During the operation, striking dilations of lymphatic vessels located on parietal pleura were observed.

At day 6, a chylothorax occurred on left side (triglyceride level $=740 \mathrm{mg} / \mathrm{dL}$ ). Total parenteral nutrition had no effect on the daily amount of chylous effusion ( $>2000 \mathrm{~mL} / \mathrm{d}$; Figure 2$)$. At day 24 , lymphography revealed a 2 -fold thoracic duct. At the level of the 10th vertebra, a left lymphopleural fistula was observed with contrast leakage into the left pleural space. The patient underwent at month $1 \mathrm{a}$ left thoracotomy with a tying as a whole of the tissues between aorta, esophagus, and vertebra. After surgery, the amount of pleural fluid decreased to half, but a right chylous effusion occurred. At month 2, tying of the right thoracic duct was performed through a thoracotomy. The amount of pleural fluid on the right side decreased progressively, allowing the removal of the chest tube. Nevertheless, repeated needle aspirations were still necessary on the same side (about $500 \mathrm{~mL}$ every 10 days). In addition, mean left chylothorax output was still greater than 1500 $\mathrm{mL} / \mathrm{d}$, despite the maintenance of total parenteral nutrition. At month 3, repeated lymphography confirmed a persistent lymphopleural fistula on both sides. Because of the persistence of the left chylothorax, an attempt of surgical closure of the lymhopleural fistula by thoracotomy was carried out at month 3.5 , associated with chemical pleurodesis with talc. Nevertheless, this procedure had no effect on the output of left chylous leakage. At month 4, somatostatin administration was added for 14 days without benefit. At month 7, the patient was still not discharged from hospital, and the daily output of left chylous effusion was more than $2000 \mathrm{~mL} / \mathrm{d}$. At this time chemical pleurodesis with povidone iodine was attempted: $40 \mathrm{~mL}$ sterile saline solution and $20 \mathrm{~mL}$ povidone iodine $10 \%$ were injected through the left chest tube, which was then clamped for 1 hour and then reconnected to $30 \mathrm{~cm} \mathrm{H}_{2} \mathrm{O}$ suction. In the 12 hours after this procedure, the chylous pleural output stopped definitively, and the chest tube could be removed after 48 hours.

The patient could be discharged to home at month 10. Repeated computed tomographic scans displayed sequelae of moderate pleural effusions on both sides, and we observed no recurrence of the chylous effusion within 2 years of follow-up.

\section{Discussion}

Chylothorax is a well-known complication after single or bilateral LT for lymphangioleiomyomatosis. Among 34 lung transplant recipients with lymphangioleiomyomatosis, Boehler and colleagues $^{1}$ reported 3 cases of postoperative chylothorax. Chylous effusion resolved in all cases after thoracic duct ligation, thoracotomy associated with medium-chain triglyceride dietary regimen, or needle aspiration. In another series, postoperative chylous fistula was observed in 4 of 12 patients who underwent LT for lymphangioleiomyomatosis. ${ }^{2}$ Favorable results were obtained in all cases after thoracic duct ligation or sclerosis. ${ }^{2}$ We report here a case of chylothorax after bilateral LT that was unusual with respect to the massive output of pleural effusion and the long-term course. The large output could be explained by the extreme severity of lymphangioleiomyomatosis before LT.

As previously reported in other cases, the chylorrhea was explained by a leakage of chylous fluid into the mediastinum from dilated and torn lymphatic vessels. ${ }^{1}$ After a 7 -month postoperative period of continuous chylous effusion despite all conventional therapies, the injection of povidone through the chest tube was the only way to stop definitively the chylous effusion.

There is no standardized treatment of chylous effusion because of its infrequent occurrence and various causes. Most authors agree that the first step should be a conservative management with medium-chain triglyceride dietary regimen or total parenteral nutrition in association with chest tube drainage. ${ }^{3}$ In case of failure of medical management, the thoracic duct can be ligated. ${ }^{3}$ For refractory chylothorax, three alternative procedures are generally considered: somatostatin administration, pleuroperitoneal shunt, and injection of sclerosing agent (eg, talc, fibrin glue) through the chest tube. ${ }^{3,4}$ Povidone iodine injection has never been described for the management of chylothorax. Nevertheless, povidone has been reported as effective in the cases of malignant pleural effusions. ${ }^{5}$. In our case we observed a dramatic efficiency of povidone within the first day after the injection. We hypothesize that povidone may have acted in inducing a true pleurodesis and also as a sclerosing agent on the abnormal lymphatic vessels. This latter hypothesis is suggested by the persistence of moderate stable chylous effusion on both sides in our patient.

In conclusion, our observations suggest that the simplicity of use and the absence of reported side effects with povidone could make it an effective therapy in cases of refractory chylothorax after LT for lymphangioleiomyomatosis. 


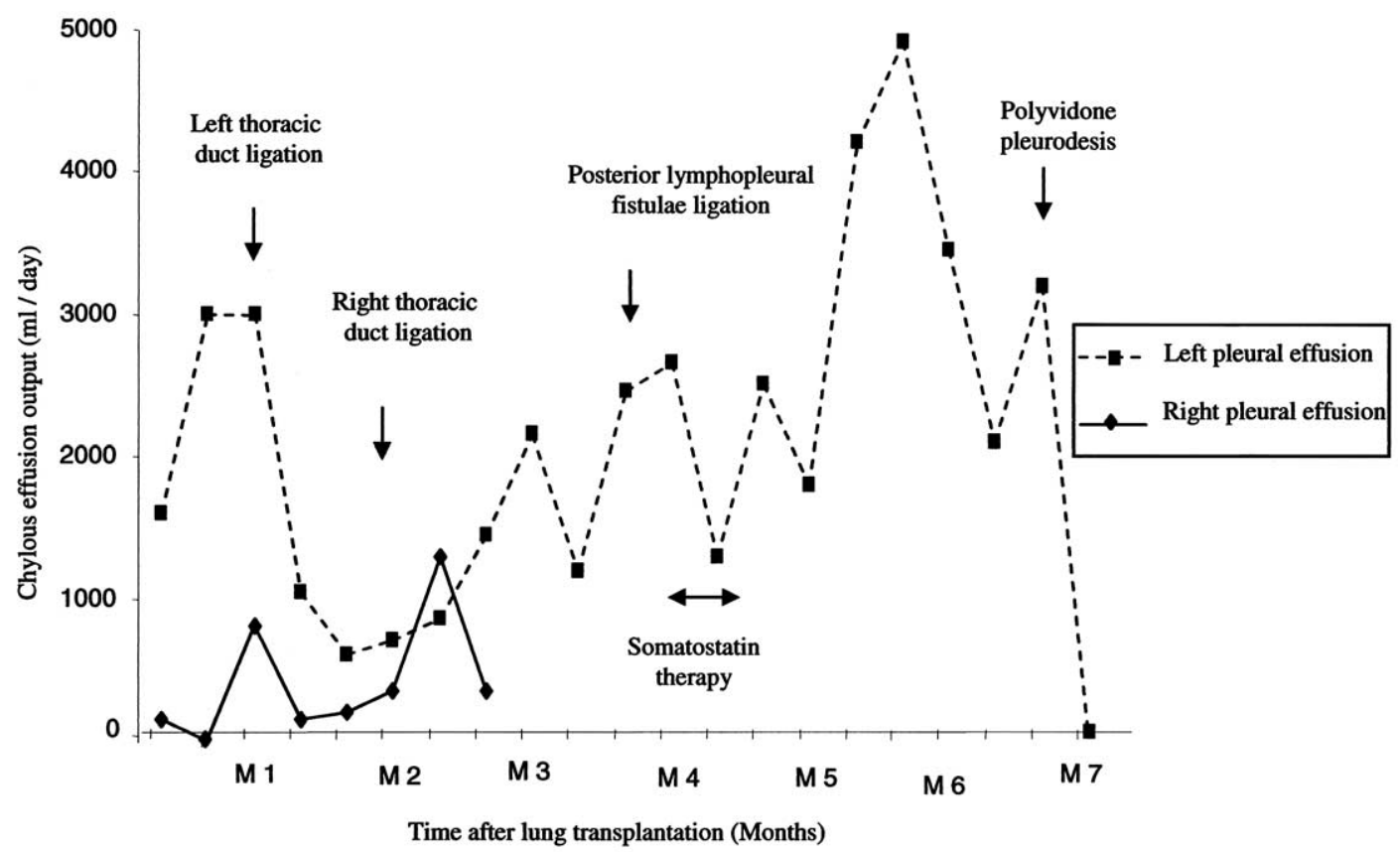

Figure 2. Evolution of chylous effusion output after LT.

\section{References}

1. Boehler A, Speich R, Russi EW, Weder W. Lung transplantation for lymphangioleiomyomatosis. $N$ Engl J Med. 1996;335:1275-80.

2. Pechet TT, Singhal AK, Meyers BF, Guthrie TJ, Battafarano RJ, Trulock EP, et al. Lung transplantation for lymphangioleiomyomatosis [abstract]. J Heart Lung Transplant. 2001;20:174.
3. Valentine VG, Raffin TA. The management of chylothorax. Chest. 1992;102:586-91.

4. Demos NJ, Kozel J, Scerbo JE. Somatostatin in the treatment of chylothorax. Chest. 2001;119:964-6.

5. Kelly-Garcia J, Roman-Berumen JF, Ibarra-Perez C. Iodopovidone and bleomycin pleurodesis for effusions due to malignant epithelial neoplasms. Arch Med Res. 1997;28:583-5.

\section{Epstein-Barr virus-associated pulmonary leiomyosarcoma arising twenty-nine years after renal transplantation}

Lorenzo Ferri, MD, ${ }^{\mathrm{a}}$ Rick Fraser, MD, ${ }^{\mathrm{b}}$ Louis Gaboury, MD, ${ }^{\mathrm{c}}$ and David Mulder, MD, ${ }^{\mathrm{a}}$ Montreal, Quebec, Canada

From the Departments of Surgery and Pathology, ${ }^{\mathrm{b}}$ McGill University, and Department of Pathology, ${ }^{\mathrm{c}}$ Centre Hospitalier de l'Université de Montréal, Montréal, Québec, Canada.

Received for publication Jan 15, 2003; accepted for publication March 17, 2003.

Address for reprints: Lorenzo Ferri, MD, McGill University Health Centre, Montreal General Hospital, Room D10.168, 1650 Cedar Ave, Montréal, Quebec H3G 1A4, Canada (E-mail: 1ferri@po-box.mcgill.ca).

J Thorac Cardiovasc Surg 2003;126:877-9

Copyright $\odot 2003$ by The American Association for Thoracic Surgery $0022-5223 / 2003 \$ 30.00+0$

doi:10.1016/S0022-5223(03)00719-0
1 $\mathrm{n}$ increased incidence of several malignancies, the most common being lymphoma and carcinoma of the skin, is a well-recognized complication of chronic immunosuppression therapy. Smooth muscle tumors arising in recipients of solid organ transplants are rare, with only 14 cases reported in the English language literature. Epstein-Barr virus $(\mathrm{EBV})$ infection has been implicated in the pathogenesis of these tumors because of diminished immune function due to immunosuppressive therapy. We report the case of a 61-year-old woman who had a leiomyosarcoma arising in a bronchus 29 years after renal transplantation. The presence of EBV was demonstrated in tumor tissue by in situ hybridization. 